\title{
High levels of Von Willebrand factor markers in COVID-19: a systematic review and meta-analysis
}

\author{
Mehrdad Rostami $^{1}$ (D) $\cdot$ Hassan Mansouritorghabeh ${ }^{1,2}$ (D) Mohammad Parsa-Kondelaji $^{1}$ (D)
}

Received: 31 August 2021 / Accepted: 19 October 2021 / Published online: 6 November 2021

(c) The Author(s), under exclusive licence to Springer Nature Switzerland AG 2021

\begin{abstract}
The SARS-CoV-2 virus has spread to all corners of the world. Thrombosis is the cause of organ failure and subsequent death in COVID-19. The pathophysiology of thrombosis in COVID-19 needs to be further explored to shed light on its downside. For this reason, this meta-analysis of Von Willebrand Factor profile (VWF: Ag, VWF: activity, VWF: RCo), ADAMTS-13, and factor VIII levels in COVID-19 was performed. To obtain data on the status of the aforementioned hemostatic factors, a systematic literature review and meta-analysis were performed on COVID-19. After reviewing the evaluation of 348 papers, 28 papers included in the meta-analysis, which was performed using STATA. The analysis showed an increase in VWF: Ag levels in COVID-19 patients. VWF: Ac was higher in all COVID-19 patients, while it was lower in the COVID-19 ICU patients. The pooled mean of VWF: RCO in all patients with COVID-19 was 307.94\%. In subgroup analysis, VWF: RCO was significantly higher in ICU patients than in all COVID-19 patients. The pooled mean of ADAMTS-13 activity was $62.47 \%$, and $58.42 \%$ in ICU patients. The pooled mean of factor VIII level was $275.8 \%$, which was significantly higher in ICU patients with COVID-19 than all patients with COVID-19. Levels of VWF: Ag, VWF: activity, VWF: ristocetin, and factor VIII are increased in patients with COVID-19. The elevated levels in ICU patients with COVID-19 suggest that these markers may have prognostic value in determining the severity of COVID-19. New therapeutic programs can be developed as a result.
\end{abstract}

Keywords COVID-19 - Thrombosis · VWF:Ag · VWF:AC · VWF:Co · ADAMTS-13 · Factor VIII level

\section{Introduction}

COVID-19 has led to severe social and economic stress worldwide [1]. It is the greatest challenge to world health. It has resulted in a large number of deaths around the globe $(4,470,969$ deaths by 28 August, 2021) [2]. Although the majority of patients suffering from with SARS-CoV-2 are asymptomatic or have mild to moderate symptoms, a proportion of patients develop a severe form of the infection and die. High age, obesity, hypertension, diabetes, and cardiovascular disease increase the risk of death [3-7]. Diffuse alveolar damage and disseminated intravascular coagulation

Hassan Mansouritorghabeh

Mansouritorghabeh@mums.ac.ir

Mehrdad Rostami

RostamiMH981@mums.ac.ir

$1 \quad$ Hematology and Blood Banking, Mashhad University of Medical Sciences, Mashhad, Iran

2 Central Diagnostic Laboratories, Ghaem Hospital, Mashhad University of Medical Sciences, Mashhad, Iran
(DIC) seem to be the main cause of death. Microthrombi are common clinical presentation in COVID-19, with an incidence of $91.3 \%$ in deceased patients of COVID-19 [8]. Microvascular thrombosis, venous thromboembolic disease, and stroke are all examples of thrombosis that can lead to embolism in multiple organs and subsequent failure. Therefore, thrombosis prevention techniques are critical in the treatment of COVID-19 [9]. Although there is increasing evidence of endothelial dysfunction and hypercoagulability in COVID-19 [10-13]. The underlying molecular mechanisms of thrombosis development in COVID-19 remain unknown. Elevated D-dimer levels are the most commonly detected coagulation abnormality in COVID-19 [14]. In severe COVID-19, elevated fibrinogen levels have been found to present a prothrombotic state that leads to thrombosis and is a predictor of mortality [15]. The transmembrane protein angiotensin-converting enzyme 2 (ACE2) allows SARS-CoV-2 to invade alveolar epithelial cells as well as endothelial cells in arteries and veins. This invasion may be accompanied by inflammation of endothelial cell damage and inflammation. Endothelial cells are a source 
of Weibel-Palade storage bodies that release prothrombotic mediators such as von Willebrand factor (VWF) and coagulation factor VIII [9]. VWF is both an inflammatory marker and a prognostic marker for endothelial dysfunction. Following infection of epithelial cells with SARS-CoV-2, the activated cell upregulate adhesion molecules and VWF, are upregulated in activated cells, leading to leukocyte recruitment, platelet activation, and activation of the complement system [16, 17]. Hepatic and endothelial cells secrete ADAMTS-13, a disntegrin and metalloprotease with a thrombospondin type 1 motif. It cleaves ultralarge multimers of VWF, reduces the extent of thrombogenicity of VWF and restores equilibrium in the hemostasis system $[12,13]$. Decreased ADAMTS-13 levels have been associated with severe and potentially fatal thrombosis [18]. Acquired deficiency of ADAMTS-13 can lead to systemic diseases such as sepsis and inflammation [19,20]. Therefore, it is plausible that COVID-19 is associated with increased thrombogenicity of VWF molecules [21]. Since ADAMTS-13 level plays an important role in the development of thrombosis, it is considered a predictor of mortality in COVID-19 patients [22].

It seems that the thrombotic consequences of COVID-19 occur over a long period of time. Thrombelastometric results in survivors of severe COVID-19 patients showed that the state of hypercoagulability may persist for up to three to four months after ICU discharge [23].

The aim of this systematic review and meta-analysis is to summarize the most current information on VWF profile (VWF: Ag, VWF: activity, VWF: RCo), factor VIII level, and ADAMTS-13 in COVID-19 patients.

\section{Material and methods}

\section{Data source and search strategy}

A systematic literature search was conducted in PubMed, Scopus, and Web of Science on March 15, 2021. The aim was to find relevant papers investigating Von Willebrand Factor profile, and factor VIII levels in COVID-19 patients. The following keywords were used as part of the search strategy in each database: "von Willebrand Factor" OR "von Willebrand" OR "VWF" OR "Willebrand Protein" OR "von Willebrand factor activity" OR "von Willebrand: Ag" OR "VWF: ag" OR "VWF: antigen" OR "von Willebrand factor ristocetin" OR "VWF: RCO" OR "Factor VIIIR-Ag" OR "AHF" OR "anti-hemophilic factor" AND "COVID-19" OR "SARS-CoV-2". On March 15, 2021, two independent authors ( $\mathrm{M} \mathrm{R}$ and M P) conducted a search and entered all papers into the EndNote $\mathrm{X} 7$ reference manager software to screen and remove duplicates.

\section{Study selection and eligibility criteria}

The following inclusion criteria were used in this metaanalysis: Articles written in English and articles examining VWF levels in COVID-19 patients. Review articles, case reports, conference articles, experimental studies or studies in animal categories, and studies with insufficient data were among the exclusion criteria used in the article search.

\section{Data extraction and quality assessment}

Two reviewers (M R and M P) independently extracted data from the final included studies to minimize bias. First author name, year of publication, country, number of patients, age and sex distribution of patients, level of VWF: Ag, level of VWF: Ac, VWF: RCO, ADAMTS-13 activity and factor VIII, if reported. The Joanna Briggs Institute (JBI) Appraisal Tool was used to determine the quality of included studies.

\section{Data synthesis and analysis}

Extracted data are reported as mean standard deviation (SD) with 95\% confidence intervals (CI). Data from articles reported as median and mean $\pm \mathrm{SD}$ were estimated with online software using the methods described by Luo et al.[24] and Wan et al. [25]. The Stata v14.0 programme (College Station, Texas, USA) was used for all statistical analyses. In interpreting the data, a two-sided P-value of less than 0.05 was considered statistically significant. The I2 test assessed heterogeneity when heterogeneity was statistically significant $(\mathrm{I} 2>50 \%)$. A random-effects model was used to account for within-study and between-study variances. Funnel plot and Begg's test were used to assess publication bias.

\section{Results}

\section{Article selection and characteristics of the articles}

The protocol for screening studies is shown in Fig. 1. The literature search retrieved 348 articles, including 99, 170, and 79 from PubMed, Scopus, and web of Science databases, 
Fig. 1 Flow diagram of selection process in the systematic Review

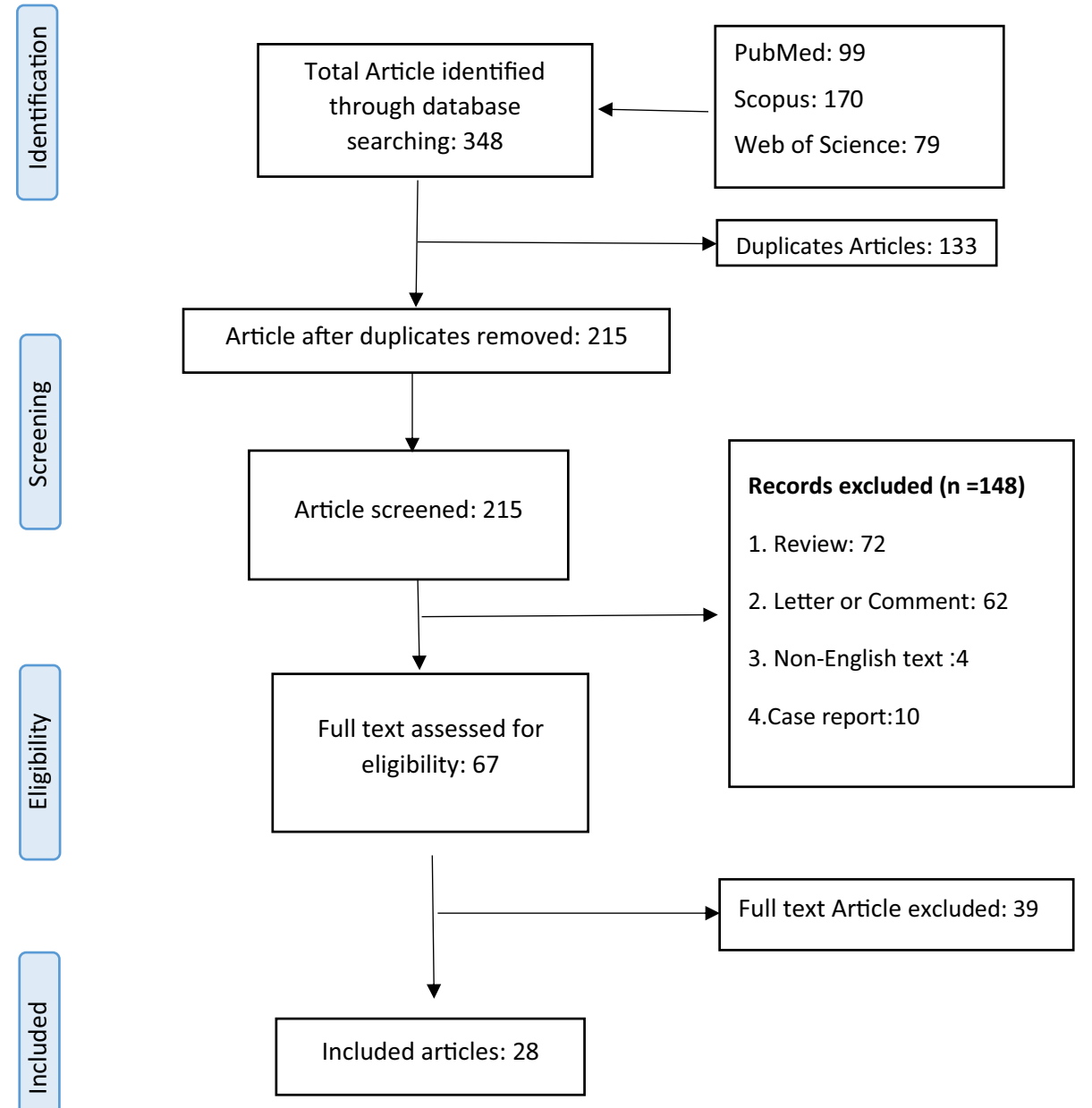

respectively. After removing duplicates, 215 publications remained. One hundred forty-eight articles were removed from the list because they were review articles or case reports or because they had unrelated titles. After this step, 67 articles were selected for full-text review, and 28 articles were included in the systematic review and meta-analysis [12, 22, 26-51]. A total of 1943 patients were analyzed in the final 28 studies used for the meta-analysis. Table 1 summarized the characteristics of the chosen studies and the characteristics of the COVID-19 patients. These studies were published between April 2020 and March 2021.

\section{Meta-analysis of VWF panel}

Plasma levels of VWF panel (VWF: Ag, VWF: AC, VWF: RCO), ADAMTS-13, and F VIII in patients with COVID-19 in the last studies examined were analyzed. Table 2 summarized all data in detail.

\section{VWF: Ag}

There were 1943 COVID-19 patients whose data from 28 papers were analyzed for the meta-analysis. Due to the high heterogeneity between studies ( $2=92.66 \%$, $p=0.00$ ), the random-effects model was used to determine the pooled mean of VWF: Ag. For all patients, VWF:Ag was $366.55 \%$ (95\% CI: 341.04-392.06, normal range: on patient wards showed an increase in VWF: Ag values in ICU COVID-19 patients. (All patients: Mean $=357.88$, 95\% CI: 327.96-387.81; I2 =93.52\%; ICU patients: Mean $=388.51,95 \%$ CI: 339.35-437.67; I2 = 87.91\%). However, as seen in Fig. 2, the difference between the subgroups was not significant. 60-150\%), as shown in Fig. 2. Subgroup analysis based 
Table 1 Summary of included studies in the meta-analysis

\begin{tabular}{|c|c|c|c|c|c|c|c|}
\hline First author & $\begin{array}{l}\text { Publication } \\
\text { Date }\end{array}$ & Study location & Study period & $\begin{array}{l}\text { Num- } \\
\text { ber of } \\
\text { patients }\end{array}$ & Age (years) & $\begin{array}{l}\text { Sex } \\
\text { (Men/Women) }\end{array}$ & Refs. \\
\hline Francesco Taus & Dec 2020 & Verona, Italy & $\begin{array}{l}\text { March } 25 \text { and May 3, } \\
2020\end{array}$ & 37 & $61.8 \pm 13.4$ & $18 / 19$ & {$[42]$} \\
\hline Fien A. von Meijenfeldt & Feb 2021 & Stockholm, Sweden & April and June, 2020 & 52 & $59(49-63)$ & $37 / 15$ & {$[45]$} \\
\hline Adrian A. N. Doevelaar, & Jan 2021 & $\begin{array}{l}\text { Essen, Hamburg, } \\
\text { Germany }\end{array}$ & NR & 75 & $66 \pm 16$ & $37 / 38$ & [48] \\
\hline George Goshua & Jun 2020 & New Haven, USA & $\begin{array}{l}\text { April } 13 \text { and April 24, } \\
2020\end{array}$ & 68 & $62 \pm 16$ & $41 / 27$ & {$[32]$} \\
\hline Annabel Blasi & Aug 2020 & Barcelona, Spain & $\mathrm{NR}$ & 23 & $64(53-74)$ & $14 / 9$ & {$[36]$} \\
\hline Wolfgang Bauer & Feb 2021 & Berlin, Germany & NR & 17 & $70.1(55.6-72)$ & $6 / 11$ & {$[40]$} \\
\hline Fien A. von Meijenfeldt & Nov 2020 & Stockholm, Sweden & $\begin{array}{l}\text { April } 9 \text { and June 8, } \\
2020\end{array}$ & 102 & $59.7 \pm 14.7$ & $65 / 37$ & {$[43]$} \\
\hline Tiffany Pascreau & Feb 2021 & Suresnes, France & NR & 70 & NR & NR & [28] \\
\hline Joseph M. Sweeney & Mar 2021 & Bronx, New York, USA & $\begin{array}{l}\text { March } 26 \text { and May 5, } \\
2020\end{array}$ & 181 & $66.2 \pm 14.6$ & $106 / 75$ & [39] \\
\hline Mario Bazzan & Jan 2020 & Turin, Italy & $\mathrm{NR}$ & 88 & $60.6 \pm 12.8$ & $60 / 28$ & {$[22]$} \\
\hline Ilaria Mancini & Nov 2020 & Milan, Italy & $\begin{array}{l}\text { March and mid-April, } \\
2020\end{array}$ & 50 & $59(27-85)$ & $32 / 18$ & [27] \\
\hline Aurélien Philippe & Dec 2020 & Paris, France & $\begin{array}{l}\text { March } 13 \text { and June 26, } \\
2020\end{array}$ & 208 & $61 \pm 16.4$ & $129 / 79$ & [29] \\
\hline $\begin{array}{l}\text { Mario Rodríguez Rod- } \\
\text { ríguez }\end{array}$ & Jan 2021 & Madrid, Spain & $\begin{array}{l}\text { March } 15 \text { and April 1, } \\
2020\end{array}$ & 100 & 60.5 & NR & {$[37]$} \\
\hline Brandon Michael Henry & Nov 2020 & Cincinnati, OH, USA & April and May, 2020 & 52 & $51(39-66)$ & $30 / 22$ & [26] \\
\hline Antoine Rauch & Aug 2020 & Lille, France & $\begin{array}{l}\text { March } 20 \text { and April 17, } \\
2020\end{array}$ & 243 & $63.9 \pm 16.2$ & $155 / 88$ & {$[30]$} \\
\hline Bingwen Eugene Fan & Oct 2020 & Singapore, Singapore & NR & 12 & $52(41-61)$ & $11 / 1$ & {$[31]$} \\
\hline Julie Helms & May 2020 & $\begin{array}{l}\text { Strasbourg Cedex, } \\
\text { France }\end{array}$ & $\begin{array}{l}\text { March } 3 \text { and March 31, } \\
2020\end{array}$ & 150 & $63(53-71)$ & $122 / 28$ & [33] \\
\hline D.J. Hoechter & Aug 2020 & Munich, Germany & $\begin{array}{l}\text { March } 4 \text { and April 4, } \\
2020\end{array}$ & 22 & $64(52-70)$ & $19 / 3$ & [34] \\
\hline Mauro Panigada & Apr 2020 & Milan, Italy & NR & 24 & $56(23-71)$ mean & NR & [12] \\
\hline Celestino Sardu & Aug 2020 & Naples, Italy & $\begin{array}{l}\text { February } 10 \text { and April } \\
20,2020\end{array}$ & 164 & $55 \pm 18$ & $108 / 56$ & {$[35]$} \\
\hline Albert Huisman & May 2020 & $\begin{array}{l}\text { Utrecht, The Nether- } \\
\text { lands }\end{array}$ & NR & 12 & $61.8(34-80)$ & $10 / 2$ & {$[38]$} \\
\hline $\begin{array}{l}\text { Nishkantha Arulku- } \\
\text { maran }\end{array}$ & Nov 2020 & London, UK & NR & 7 & $53(45-60)$ & $3 / 4$ & [41] \\
\hline Peter L. Turecek & Feb 2021 & $\begin{array}{l}\text { Bristol, United King- } \\
\text { dom }\end{array}$ & $\begin{array}{l}\text { March } 19 \text { and May 7, } \\
2020\end{array}$ & 36 & $61(23-76)$ & $28 / 8$ & [44] \\
\hline Paul Masi & Aug 2020 & Paris, France & $\mathrm{NR}$ & 17 & $48(42-58)$ & $12 / 5$ & [46] \\
\hline Eleni E Ladikou & Sep 2020 & Brighton, UK & NR & 24 & $65(55-72)$ & $18 / 6$ & [47] \\
\hline Soracha E.Ward & Dec 2020 & Dublin, Ireland & $\begin{array}{l}\text { March } 21 \text { and May 6, } \\
2020\end{array}$ & 28 & $55(27-75)$ & $22 / 6$ & [49] \\
\hline Franco Ruberto & Jan 2021 & Rome, Italy & April and May, 2020 & 19 & $69 \pm 12.8$ & $10 / 9$ & {$[50]$} \\
\hline Maxime Delrue & Dec 2020 & Paris, France & $\begin{array}{l}\text { March } 17 \text { and April 11, } \\
2020\end{array}$ & 133 & $65.5 \pm 15.4$ & $97 / 36$ & {$[51]$} \\
\hline
\end{tabular}

Data Reported as range, mean $\pm \mathrm{SD}$, or median (interquartile range)

Abbreviations: NR, not reported; Ref, Reference 
Table 2 Meta-analysis of VWF panel, ADAMTS-13, and factor VIII in COVID-19 patients

\begin{tabular}{llllll}
\hline Parameters & No. studies & No. patients & Mean & $(95 \% \mathrm{CI})$ & Reference range \\
\hline VWF: Ag (\%) & 28 & 1943 & 366.55 & $341.04-392.06$ & $60-150 \%$ \\
VWF: Ac (\%) & 6 & 334 & 301.85 & $268.21-335.48$ & $50-150 \%$ \\
VWF: RCo (\%) & 8 & 494 & 307.94 & $264.37-351.5$ & $40-150 \%$ \\
ADAMTS13 activity (\%) & 12 & 859 & 62.47 & $55.18-69.76$ & $60-150 \%$ \\
F VIII (\%) & 18 & 1154 & 275.8 & $238.27-313.33$ & $50-150 \%$ \\
\hline
\end{tabular}

Abbreviations: $C I$, Confidence interval; $N o$, number; $A g$, antigen; $A C$, activity; $R C o$, Ristocetin Cofactor; $V W F$, von Willebrand Factor

\section{VWF: Ac}

Regarding analysis of VWF: Ac, it was measured in six studies involving 334 patients. Since, the heterogeneity of VWF: Ac among these studies was high (I $2=82.68 \%$, $p=0.00$ ), the random-effects model was used to analyze the data. The pooled mean of VWF: Ac was 301.85\% (95\% CI: 268.21-335.48, normal range: 50-150\%). In subgroup analysis; VWF: Ac decreased in COVID-19 patents in ICU patients subgroup, (All COVID-19 patients: Mean $=328.44$, 95\% CI: 299.53-357.36; I2 $=49.34 \%$; ICU patients: Mean $=275.51,95 \%$ CI: $236.69-314.32 ; \mathrm{I} 2=62.53 \%)$ and the test of subgroup differences was significant $(p=0.03)$ (Fig. 3).

\section{VWF: RCO}

Eight papers with 494 COVID-19 patients were selected for VWF: RCO meta-analysis. Due to the high heterogeneity ( $\mathrm{I} 2=91.37 \%, p=0.00)$, the random-effects model was used for the analysis, and the pooled mean of VWF:RCO in all patients with COVID-19 was $307.94 \%$ (95\% CI: 264.37-351.5, normal range: 40-150\%). In subgroup analysis, there was a significant difference between all COVID-19 patients and ICU patients. (All COVID-19 patients: Mean $=270.14,95 \%$ CI: 215.67-324.61; I2 $=94 \%$; ICU patients: Mean $=356.89$, 95\% CI: $324.23-389.56$; I2 $=14.88 \%$; difference group test, $p=0.01$ ) (Fig. 4).

\section{ADAMTS-13 activity}

A total of 12 papers with 859 COVID-19 patients were included in the meta-analysis. A high heterogeneity was found between studies ( $\mathrm{I} 2=95 \%, p=0.00$ ). Consequently, the random-effects model was used for the analysis, which showed that the pooled mean of ADAMTS-13 activity in all patients was $62.47 \%$ (95\% CI: 55.18-69.76, normal range: $60-150 \%)$. Subgroup analysis showed no significant difference $(\mathrm{p}=0.59)$ (All COVID-19 patients: Mean $=63.56$ 95\% CI: 55.22-71.91; I2 $=96.19 \%$; ICU patients: Mean $=58.42,95 \%$ CI: 41.74-75.10; I $2=77.91 \%)($ Fig. 5).

\section{Coagulation factor VIII (FVIII)}

Of 18 papers that measured FVIII levels, 1154 COVID-19 patients were included. The pooled mean was $275.8 \%$ (95\% CI: $238.27-313.33$, normal range: $50-150 \%$ ) with high heterogeneity (I $2=97.47 \%, p=0.00)$. Despite the high heterogeneity between papers on FVIII levels in COVID19 , subgroup difference analysis was significant ( $p$-value: 0.00) (All COVID-19 patients: $M e a n=238.93$ 95\% CI: 205.66-272.2; I2 = 96.35\%; ICU patients: Mean $=342.47$, 95\% CI: $279.57-405.37 ;$ I2 $=92.01 \%$ ) (Fig. 6).

\section{Publication bias}

A plotted Begg's Funnel plot for VWF: Ag levels showed that the $p$-value of Begg's test was 0.342 (Fig. 7). The Begg's test for VWF: Ag showed that there was no stable evidence of publication bias in the meta-analysis.

\section{Discussion}

The findings of the current meta-analysis revealed that plasma levels of the VWF profile (VWF: Ag, VWF: Ac, and VWF: RCo) are increased in patients with COVID-19. The levels of these markers are higher in ICU patients than in all COVID-19 patients, with the exception of VWF: Ac. These findings may explain why VWF is involved in the development of thrombosis in COVID-19. VWF: Ac levels were lower in ICU patients than in all COVID-19 patients, 


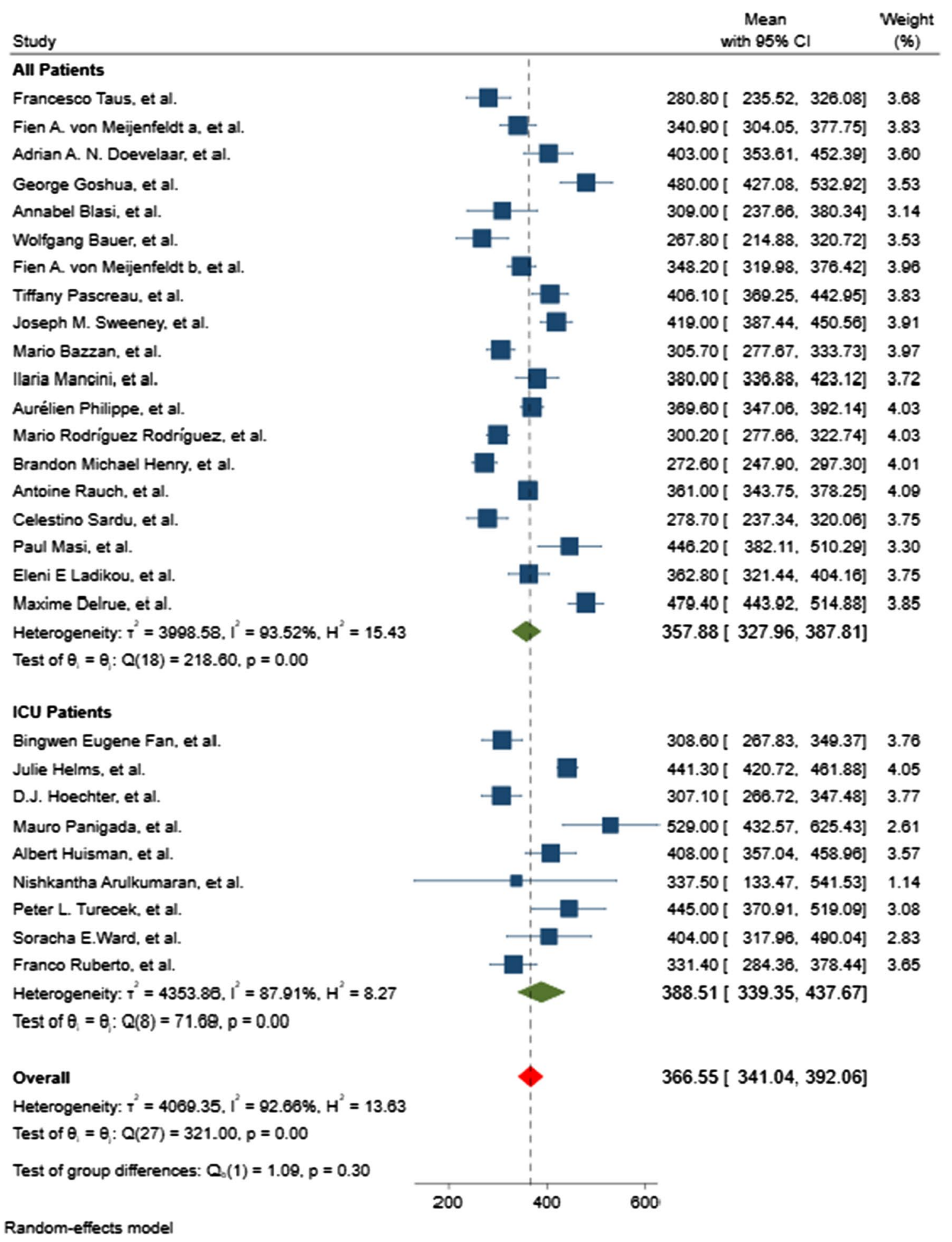

Fig. 2 The forest plot of the mean in the VWF: Ag levels in COVID-19 patients

perhaps due to the interaction of VWF with FVIII and platelets and subsequent consumption.
High molecular weight multimers (HMWM) of VWF play a central role in the development of thrombosis. This 
Fig. 3 The forest plot of the mean in the VWF: Ac levels in COVID-19 patients
Fig. 4 The forest plot of the mean in the VWF: RCO levels in COVID-19 patients

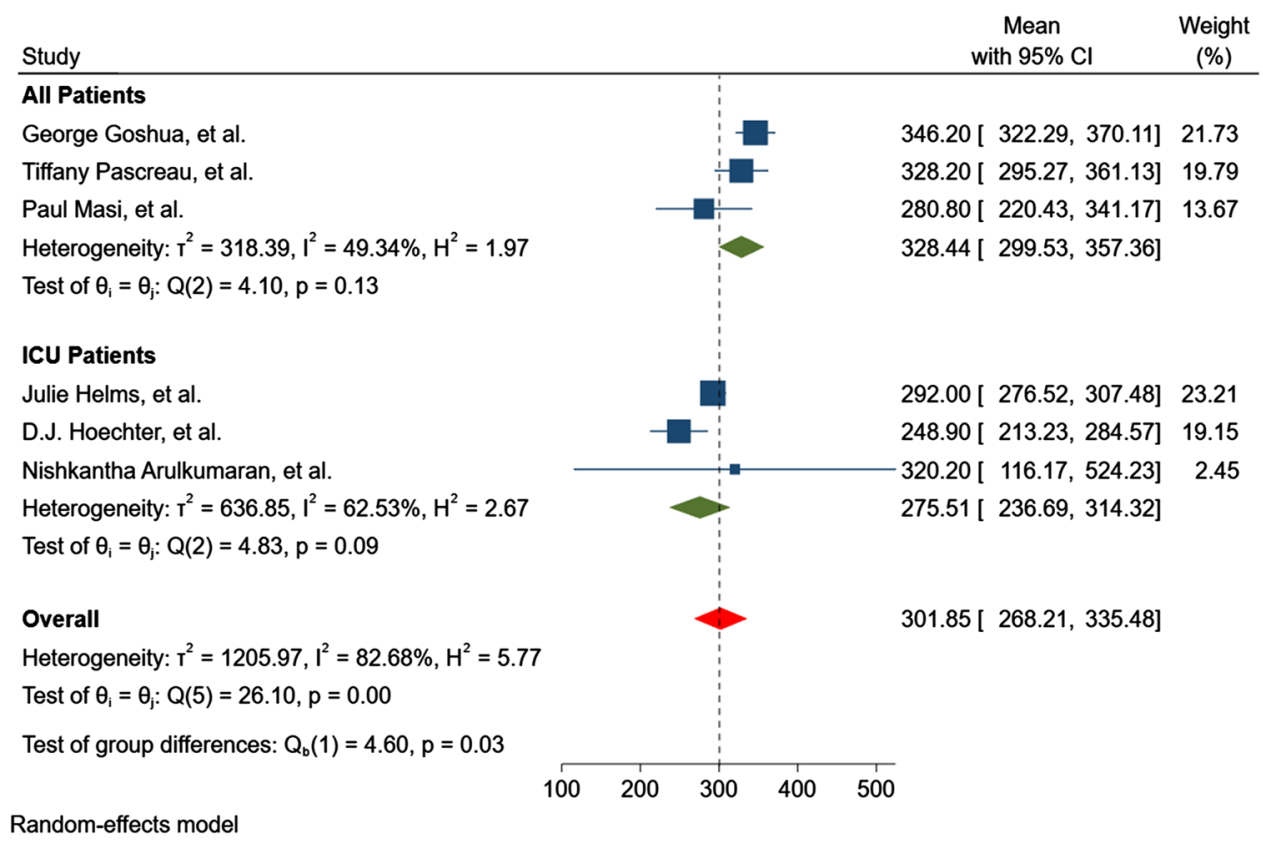

Random-effects model

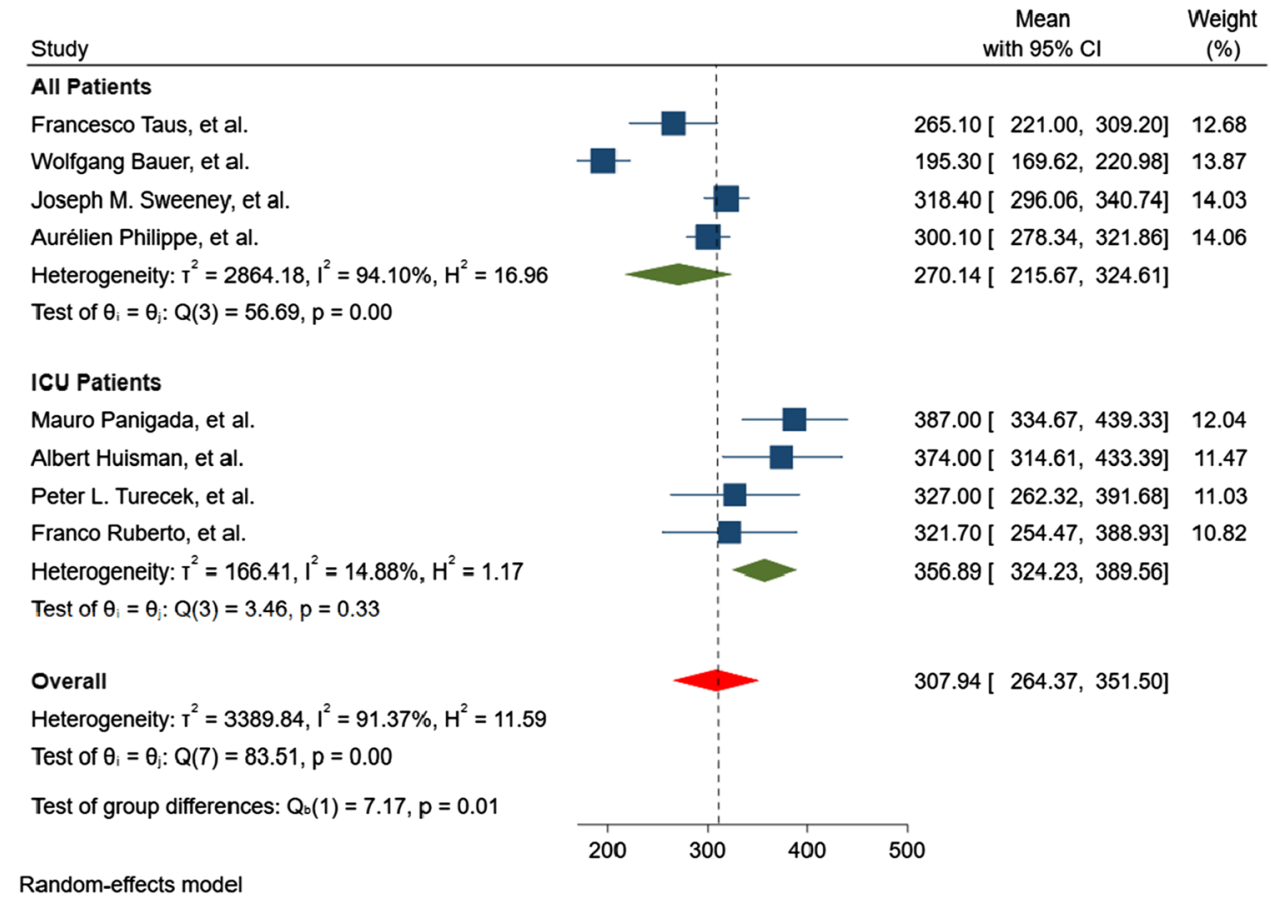

is because the adhesive properties of VWF depend on the size of the multimers, which are typically between 5000 and $10,000 \mathrm{KDa}$. The HMWM with a size of 5000-10,000 KDa are more active in the interaction between platelet receptors and collagen, therefore they are more thrombogenic in shear stress [52]. On the other hand, VWF is the carrier of factor VIII in plasma. It protects factor VIII from accelerated clearance and thus increases the half-life of factor VIII [53, 


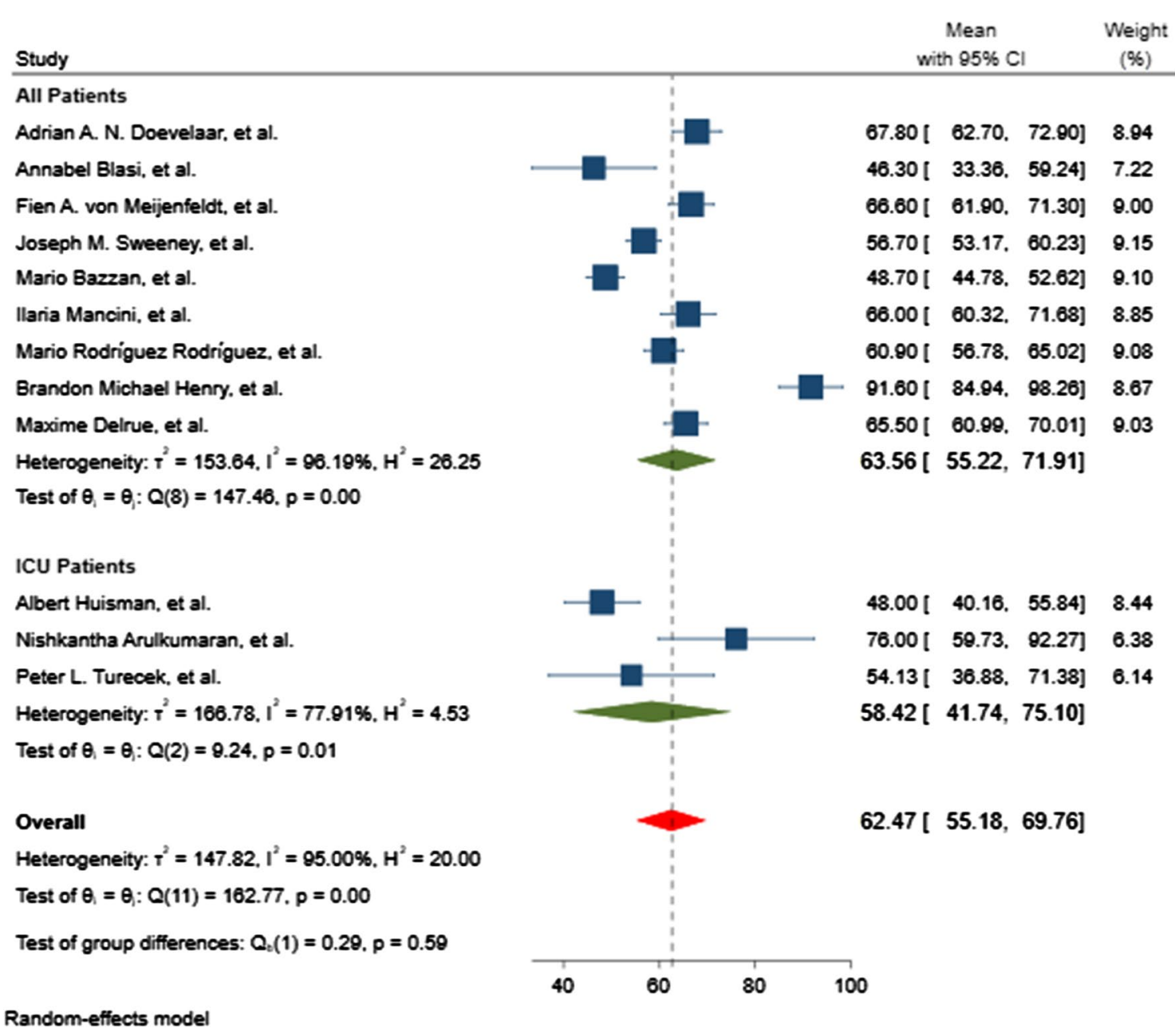

Fig. 5 The forest plot of the mean in the ADAMTS-13 activity in COVID-19 patients

54]. The plasma levels of FVIII in COVID-19 patients were shown to be increased in this meta-analysis. Compared with all COVID-19 patients, the factor VIII levels were statistically higher in ICU patients with COVID-19. Elevated plasma FVIII levels can be considered as a thrombogenic factor.

According to the radiological findings, pulmonary embolism (PE) may differ from conventional PE in patients with COVID-19. It seems that there are more local in situ immunothrombosis in COVID-19 than typical conventional venous thrombosis [51]. Therefore, the pathophysiology of thrombosis in COVID-19 remains to be thoroughly investigated.

In COVID-19, certain potential players seems to be involved in the interplay between coagulation system's activation and inflammation. Thus, several biomarkers in COVID-19 have been proposed as predictors of COVI-19 severity [52].

The limitation with this meta-analysis was the concern with the method of ADAMTS-13 determination. The recruited 12 publications about ADAMTS-13 in COVID-19, researchers measured it using different methods. We presented the data in one analysis because their normal values were virtually identical.

In light of these results, it is proposed that the following topics be investigated:

(1) Analysis of VWF multimers in patients with COVID19 in different type of COVID-19 (mild, moderate, and severe). While there are no ultra large VWF in plasma of healthy people due to rapid proteolysis by ADAMTS-13 function [55]. In patients with deficiency or lack of ADAMTS-13, accumulation of ultra large VWF is observed on the surface of endothelial cells and in plasma. Interestingly, the obtained results show that high VWF levels were associated with lower ADAMTS13 levels, suggesting an imbalance between the increased production of this highly thrombogenic protein and a relative decrease in the enzyme responsible for its removal. There is a gap in the literature 


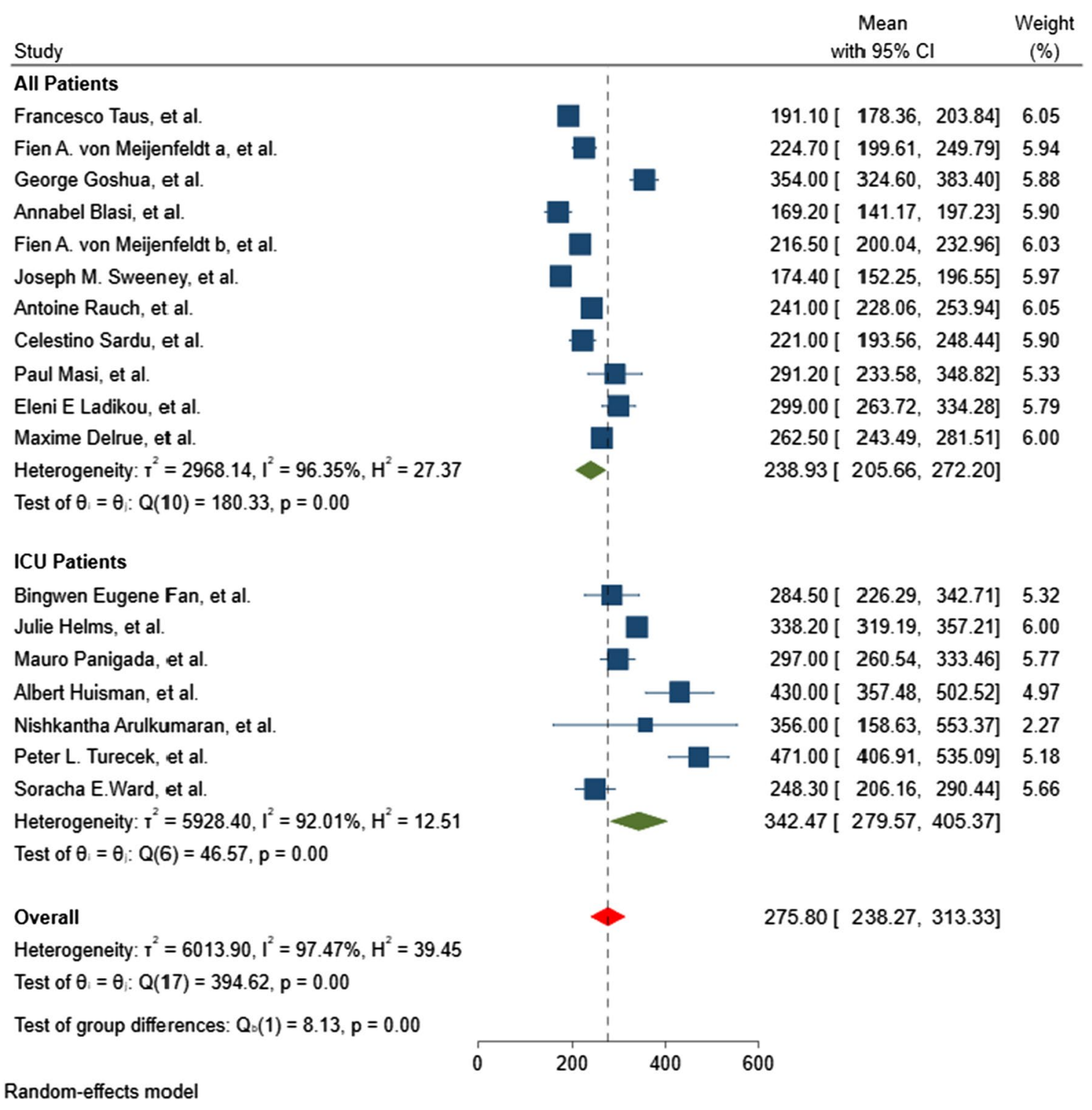

Fig. 6 The forest plot of the mean in the F VIII levels in COVID-19 patients

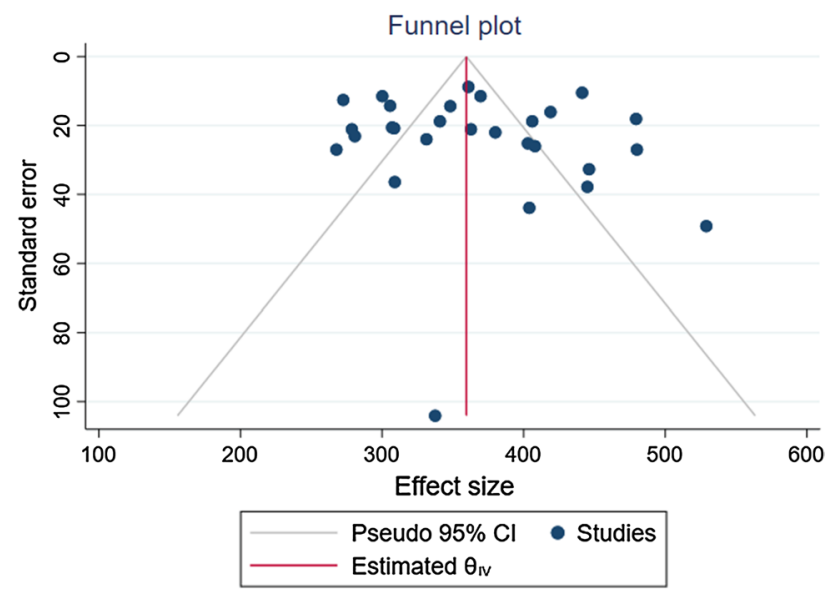

Fig. 7 Funnel plot of the VWF: Ag levels among patients with COVID-19 about the possible existence of ultra large VWF in severe COVID-19 infection. Therefore, it is logical to investigate VWF multimers in COVID-19.

(2) The harmacokinetics of factor VIII in plasma of patients with COVID-19 should be studied to define the half-life of factor VIII at different stages of COVID-19.

(3) Additional markers such as antiphospholipid antibodies and heparin-induced thrombocytopenia have been suggested for further investigation to decipher the pathophysiology of thrombosis in COVID-19 [56-58]. 
Author contributions RM and PM did the literature search, metaanalysis, interpreted the results, and wrote the result section. MH did idea, interoperated the result and wrote the draft.

Funding There was no fund for the current report.

Availability of data and materials The raw materials can be requested by communication with corresponding author.

\section{Declarations}

Conflict of interest The authors have no relevant affiliations or financial involvement with any organization or entity with a financial interest in or financial conflict with the subject matter or materials discussed in the manuscript. This includes employment, consultancies, honoraria, stock ownership or options, expert testimony, grants or patents received or pending, or royalties.

Ethics approval The local ethics committee in Mashhad University of Medical Sciences approved this study.

\section{References}

1. Ahmad M, Iqbal M, Drissi J, Hassan A. Modeling of Supply Chain Sustainability Enablers by Considering the Impact of COVID-19 on Developing Countries.

2. WHO. WHO Coronavirus Disease (COVID-19) Dashboard 2021. Available at: https://covid19.who.int/. Accessed in August 29, 2021

3. Gao F, Zheng KI, Wang X-B, et al. Obesity is a risk factor for greater COVID-19 severity. Diabetes Care. 2020;43:e72-4.

4. Cook T. The importance of hypertension as a risk factor for severe illness and mortality in COVID-19. Anaesthesia. 2020;75:976-7.

5. Seiglie J, Platt J, Cromer SJ, et al. Diabetes as a risk factor for poor early outcomes in patients hospitalized with COVID-19. Diabetes Care. 2020;43:2938-44

6. Bansal M. Cardiovascular disease and COVID-19. Diabetes Metab Syndr. 2020;14:247-50.

7. Daoust J-F. Elderly people and responses to COVID-19 in 27 Countries. PLoS ONE. 2020;15:e0235590.

8. Chen W, Pan JY. Anatomical and pathological observation and analysis of SARS and COVID-19: microthrombosis is the main cause of death. Biol Proc Online. 2021;23:1-12.

9. McFadyen JD, Stevens H, Peter K. The emerging threat of (micro) thrombosis in COVID-19 and its therapeutic implications. Circ Res. 2020;127:571-87.

10. Middeldorp S, Coppens M, van Haaps TF, et al. Incidence of venous thromboembolism in hospitalized patients with COVID19. J Thromb Haemost. 2020;18:1995-2002.

11. Bikdeli B, Madhavan MV, Jimenez D, et al. COVID-19 and thrombotic or thromboembolic disease: implications for prevention, antithrombotic therapy, and follow-up: JACC state-of-theart review. J Am Coll Cardiol. 2020;75:2950-73.

12. Panigada M, Bottino N, Tagliabue P, et al. Hypercoagulability of COVID-19 patients in intensive care unit: a report of thromboelastography findings and other parameters of hemostasis. J Thromb Haemost. 2020;18:1738-42.

13. Cugno M, Meroni PL, Gualtierotti R, et al. Complement activation in patients with COVID-19: a novel therapeutic target. J Allergy Clin Immunol. 2020;146:215-7.
14. Rostami M, Mansouritorghabeh H. D-dimer level in COVID19 infection: a systematic review. Expert Rev Hematol. 2020;13:1265-75.

15. Zhang Y, Cao W, Jiang W, et al. Profile of natural anticoagulant, coagulant factor and anti-phospholipid antibody in critically ill COVID-19 patients. J Thromb Thrombolysis. 2020;50:580-6.

16. Aird WC. The role of the endothelium in severe sepsis and multiple organ dysfunction syndrome. Blood J Am Soc Hematol. 2003;101:3765-77.

17. Kayal S, Jaïs J-P, Aguini N, et al. Elevated circulating E-selectin, intercellular adhesion molecule 1 , and von Willebrand factor in patients with severe infection. Am J Respir Crit Care Med. 1998;157:776-84.

18. Levy GG, Nichols WC, Lian EC, et al. Mutations in a member of the ADAMTS gene family cause thrombotic thrombocytopenic purpura. Nature. 2001;413:488-94.

19. Chen J, Chung DW. Inflammation, von Willebrand factor, and ADAMTS13. Blood. 2018;132:141-7.

20. Levi M, Scully M, Singer M. The role of ADAMTS-13 in the coagulopathy of sepsis. J Thromb Haemost. 2018;16:646-51.

21. Morici N, Bottiroli M, Fumagalli R, et al. Role of von Willebrand factor and ADAMTS-13 in the pathogenesis of thrombi in SARS-CoV-2 infection: time to rethink. Thromb Haemost. 2020;120:1339-42.

22. Bazzan M, Montaruli B, Sciascia S, et al. Low ADAMTS 13 plasma levels are predictors of mortality in COVID-19 patients. Intern Emerg Med. 2020;15:861-3.

23. Magomedov A, Zickler D, Karaivanov S et al. COVID-19 Associated coagulopathy is a reversible phenomenon-3-month follow up reveals normalization of coagulation status associated with complete venous recanalization in patients after severe COVID19. 2021.

24. Luo D, Wan X, Liu J, Tong T. Optimally estimating the sample mean from the sample size, median, mid-range, and/or mid-quartile range. Stat Methods Med Res. 2018;27:1785-805.

25. Wan X, Wang W, Liu J, Tong T. Estimating the sample mean and standard deviation from the sample size, median, range and/or interquartile range. BMC Med Res Methodol. 2014;14:1-13.

26. Henry BM, Benoit SW, de Oliveira MHS, et al. ADAMTS13 activity to von Willebrand factor antigen ratio predicts acute kidney injury in patients with COVID-19: Evidence of SARS-CoV-2 induced secondary thrombotic microangiopathy. Int J Lab Hematol. 2020. https://doi.org/10.1111/ijlh.13415.

27. Mancini I, Baronciani L, Artoni A, et al. The ADAMTS13-von Willebrand factor axis in COVID-19 patients. J Thromb Haemost. 2021;19:513-21.

28. Pascreau T, Zia-Chahabi S, Zuber B, et al. ADAMTS 13 deficiency is associated with abnormal distribution of von Willebrand factor multimers in patients with COVID-19. Thromb Res. 2021. https://doi.org/10.1016/j.thromres.2021.02.008.

29. Philippe A, Chocron R, Gendron N et al. Circulating Von Willebrand factor and high molecular weight multimers as markers of endothelial injury predict COVID-19 in-hospital mortality. Angiogenesis 2021.

30. Rauch A, Labreuche J, Lassalle F, et al. Coagulation biomarkers are independent predictors of increased oxygen requirements in COVID-19. J Thromb Haemost. 2020;18:2942-53.

31. Fan BE, Ng J, Chan SSW, et al. COVID-19 associated coagulopathy in critically ill patients: A hypercoagulable state demonstrated by parameters of haemostasis and clot waveform analysis. J Thromb Thrombolysis. 2020. https://doi.org/10.1007/ s11239-020-02318-x.

32. Goshua G, Pine AB, Meizlish ML, et al. Endotheliopathy in COVID-19-associated coagulopathy: evidence from a singlecentre, cross-sectional study. Lancet Haematol. 2020;7:e575-82. 
33. Helms J, Tacquard C, Severac F, et al. High risk of thrombosis in patients with severe SARS-CoV-2 infection: a multicenter prospective cohort study. Intensive Care Med. 2020;46:1089-98.

34. Hoechter DJ, Becker-Pennrich A, Langrehr J, et al. Higher procoagulatory potential but lower DIC score in COVID-19 ARDS patients compared to non-COVID-19 ARDS patients. Thromb Res. 2020;196:186-92.

35. Sardu C, Marfella R, Maggi P, et al. Implications of AB0 blood group in hypertensive patients with covid-19. Bmc Cardiovasc Disord. 2020. https://doi.org/10.1186/s12872-020-01658-z.

36. Blasi A, von Meijenfeldt FA, Adelmeijer J, et al. In vitro hypercoagulability and ongoing in vivo activation of coagulation and fibrinolysis in COVID-19 patients on anticoagulation. J Thromb Haemost. 2020;18:2646-53.

37. Rodríguez Rodríguez M, Castro Quismondo N, Zafra Torres D, et al. Increased von Willebrand factor antigen and low ADAMTS13 activity are related to poor prognosis in covid-19 patients. Int J Lab Hematol. 2021. https://doi.org/10.1111/ijlh. 13476.

38. Huisman A, Beun R, Sikma M, et al. Involvement of ADAMTS13 and von Willebrand factor in thromboembolic events in patients infected with SARS-CoV-2. Int J Lab Hematol. 2020;42:e211-2.

39. Sweeney JM, Barouqa M, Krause GJ, et al. Low ADAMTS13 activity correlates with increased mortality in COVID-19 patients. TH Open. 2021;5:e89-103.

40. Bauer W, Galtung N, Neuwinger N, et al. A matter of caution: coagulation parameters in COVID-19 do not differ from patients with ruled-out SARS-CoV-2 infection in the emergency department. TH Open. 2021;5:e43-55.

41. Arulkumaran N, Thomas M, Brealey D, et al. Plasma exchange for COVID-19 thrombo-inflammatory disease. EJHaem. 2020. https:// doi.org/10.1002/jha2.140.

42. Taus F, Salvagno G, Cane S, et al. Platelets promote thromboinflammation in SARS-CoV-2 pneumonia. Arterioscler Thromb Vasc Biol. 2020;40:2975-89.

43. von Meijenfeldt FA, Havervall S, Adelmeijer J, et al. Prothrombotic changes in patients with COVID-19 are associated with disease severity and mortality. Res Pract Thromb Haemost. 2021;5:132-41.

44. Turecek PL, Peck RC, Rangarajan S, et al. Recombinant ADAMTS13 reduces abnormally up-regulated von Willebrand factor in plasma from patients with severe COVID-19. Thromb Res. 2021;201:100-12.

45. von Meijenfeldt FA, Havervall S, Adelmeijer J, et al. Sustained prothrombotic changes in COVID-19 patients 4 months after hospital discharge. Blood Adv. 2021;5:756-9.

46. Masi P, Hékimian G, Lejeune M, et al. Systemic inflammatory response syndrome is a major contributor to COVID-19-associated coagulopathy: insights from a prospective, single-center cohort study. Circulation. 2020;142:611-4.
47. Ladikou EE, Sivaloganathan H, Milne KM, et al. Von Willebrand factor (vWF): marker of endothelial damage and thrombotic risk in COVID-19? Clin Med. 2020;20:E178-82.

48. Doevelaar AAN, Bachmann M, Hölzer B, et al. von Willebrand Factor Multimer Formation Contributes to Immunothrombosis in Coronavirus Disease 2019. Crit Care Med. 2021. https://doi.org/ 10.1097/CCM.0000000000004918.

49. Ward SE, Curley GF, Lavin M, et al. Von Willebrand factor propeptide in severe coronavirus disease 2019 (COVID-19): evidence of acute and sustained endothelial cell activation. Br J Haematol. 2021;192:714-9.

50. Ruberto F, Chistolini A, Curreli M, et al. Von Willebrand factor with increased binding capacity is associated with reduced platelet aggregation but enhanced agglutination in COVID-19 patients: another COVID-19 paradox? J Thromb Thrombolysis. 2021. https://doi.org/10.1007/s11239-020-02339-6.

51. Delrue M, Siguret V, Neuwirth M, et al. von Willebrand factor/ADAMTS13 axis and venous thromboembolism in moderate-to-severe COVID-19 patients. Br J Haematol. 2020;192(6):1097-100.

52. Stockschlaeder M, Schneppenheim R, Budde U. Update on von Willebrand factor multimers: focus on high-molecular-weight multimers and their role in hemostasis. Blood Coag Fibrinol. 2014;25:206.

53. Nogami K, Shima M, Nishiya K, et al. A novel mechanism of factor VIII protection by von Willebrand factor from activated protein C-catalyzed inactivation. Blood J Am Soc Hematol. 2002;99:3993-8.

54. Rosenberg JB, Foster PA, Kaufman RJ, et al. Intracellular trafficking of factor VIII to von Willebrand factor storage granules. J Clin Investig. 1998;101:613-24.

55. Sporn LA, Marder VJ, Wagner DD. Inducible secretion of large, biologically potent von Willebrand factor multimers. Cell. 1986;46:185-90.

56. Warkentin TE, Kaatz S. COVID-19 versus HIT hypercoagulability. Thromb Res. 2020. https://doi.org/10.1016/j.thromres.2020. 08.017 .

57. Galeano-Valle F, Oblitas C, Ferreiro-Mazón M, et al. Antiphospholipid antibodies are not elevated in patients with severe COVID-19 pneumonia and venous thromboembolism. Thromb Res. 2020;192:113.

58. Fletcher-Sandersjöö A, Bellander B-M. Is COVID-19 associated thrombosis caused by overactivation of the complement cascade? a literature review. Thrombosis Research 2020

Publisher's Note Springer Nature remains neutral with regard to jurisdictional claims in published maps and institutional affiliations. 